\title{
Papan Pergantian Pemain Sepak Bola Berbasis Digital Menggunakan IC4072 dan IC7447
}

\author{
Teguh Arifianto \\ Program Studi Teknik Informatika, STMIK Yadika Bangil \\ teguh.arifianto.1988@stmik-yadika.ac.id
}

\begin{abstract}
ABSTRAK
Semua rangkaian elektronika pada umumnya menggunakan komponen tabung hampa (vaccum tube) atau komponen diskrit seperti dioda dan transistor. Terkait dengan perkembangan teknologi dalam bidang elektronika, baik rangkaian maupun komponen mengalami perkembangan yang begitu pesat. Sehingga setiap rangkaian elektronika dibentuk oleh komponen semikonduktor yang disebut sistem digital. Di dalam dunia olahraga, konsep digital dapat diterapkan. Salah satunya adalah olahraga sepak bola. Di dalam sepak bola, papan angka sangat dibutuhkan. $\mathrm{Hal}$ tersebut untuk memudahkan pergantian pemain oleh sebuah tim. Sebagian stadion di Indonesia masih menggunakan papan pergantian pemain secara manual. Dalam perkembangan rangkaian pergantian pemain saat ini masih menggunakan mikrokontroler. Namun, di dalam rangkaian mikrokontroler tersebut terdapat banyak kelemahan antara lain, efisiensi penggunaannya kurang begitu baik karena hanya untuk menampilkan angka 0 sampai 9 menggunakan bahasa pemrograman komputer. Penggunaan papan angka berbasis IC (Integrated Circuit) lebih sederhana karena dalam pembuatannya tidak memerlukan bahasa pemrograman hanya menggunakan rangkaian dasar elektronika. Apabila dalam kerusakannya lebih mudah ditangani dan tidak membutuhkan banyak biaya dan waktu. Rangkaian ini merupakan alat yang digunakan untuk mempermudah penggantian pemain sepak bola berbasis digital dengan tampilan berupa angka pada seven segment.
\end{abstract}

Kata Kunci: rangkaian elektronika, dioda, transistor, sistem digital, sepak bola, mikrokontroler, IC (Integrated Circuit), seven segment 


\section{PENDAHULUAN}

Di zaman sekarang ini teknologi berkembang dengan pesat dan mencakup segala bidang seperti bidang elektro, pendidikan, olahraga, kedokteran, dan lain-lain. Pada awal teknologi ditemukan, hampir semua elektronik umumnya menggunakan tabung hampa (vaccum tube) atau komponen diskrit seperti dioda dan transistor, sehingga semua peralatan elektronik secara fisik bentuknya besar.

Kemajuan teknologi sekarang ini setiap rangkaian elektronik dibentuk oleh komponen semikonduktor yang disebut sistem digital. Hal ini memungkinkan seseorang dapat membuat rangkaian peralatan elektronik hanya dengan menghubungkan beberapa buah chip/modul IC (Integrated Circuit) tanpa harus memikirkan sistem perkabelan yang ada di dalam rangkaian tersebut. Karena semakin majunya teknologi, terutama dengan diterapkannya prinsip-prinsip yang menggunakan komponen semikonduktor yang dapat dipergunakan sebagai peralatan saklar (switching device). Sistem saklar ini merupakan suatu sistem yang dapat dipergunakan sebagai dasar dalam pembuatan peralatan yang dapat bekerja secara otomatis. Sistem saklar prinsip kerjanya adalah berdasarkan ada dan tidaknya aliran listrik. Demikian pula peralatan elektronika mutakhir seperti jam digital, komputer, kalkulator, papan digital, dan lainlain yang dirancang menggunakan sistem logika yang pada dasarnya juga menggunakan sistem saklar atau switching device.

Dalam dunia olahraga, konsep digital dapat diterapkan. Salah satunya adalah olahraga sepak bola. Permainan sepak bola pada khususnya dibahas dalam penulisan ini dan permainan olahraga lainnya pada umumnya. Pergantian pemain merupakan hal yang pasti dilakukan dalam pertandingan sepak bola. Sebagian kecil stadion yang berada di Indonesia, dalam hal pergantian pemain khususnya papan angka yang digunakan masih berbasis mikrokontroler.

Dalam penggunaannya terdapat 10 switch serta dapat menghemat catu daya. Namun, dalam penggunaan mikrokontroler juga terdapat kekurangan yaitu efisiensi penggunaannya kurang begitu baik karena hanya untuk menampilkan angka 0 sampai 9 menggunakan bahasa pemrograman komputer serta biaya yang dikeluarkan sangatlah besar. Kerusakan dalam mikrokontroler sulit ditangani karena dalam perbaikan membutuhkan sebuah code untuk menanganinya.

Penggunaan IC dalam rangkaian papan pergantian pemain sangatlah diperlukan karena penggunaan IC lebih efisien daripada penggunaan mikrokontroler. Untuk memunculkan angka 0-9 dengan menggunakan IC, cukup hanya menggunakan elektronika dasar. Biaya yang dibutuhkan lebih murah. Kerusakan yang dialami mudah ditangani karena tidak menggunakan code komputer. Human error dalam penggunaan mudah ditangani seketika. Namun, penggunaan IC juga terdapat kelemahan yaitu dalam penggunaan memerlukan catu daya yang boros. Teknik switching yang lebih banyak karena menggunakan 36 switch.

$$
\text { Rangkaian ini dapat }
$$

memberikan kemudahan dalam pergantian sepak bola. Selain itu, rangkaian ini dapat meningkatkan efisiensi waktu dalam pertandingan. 


\section{TINJAUAN PUSTAKA}

Dalam tinjauan pustaka ini akan dibahas konsep dan teori-teori dasar yang berhubungan dengan pembuatan papan angka berbasis digital.

\section{Perancangan Sistem}

Rangkaian pergantian pemain sepak bola ini terdiri dari kabel, papan PCB, IC4072, IC7447, dan seven segment. Dimana kabel di sini digunakan sebagai penghantar arus listrik ke tiap komponen input IC. Papan PCB digunakan untuk membuat jalur dari sebuah input IC ke output atau dari output yang sebelumnya akan dimasukkan ke input rangkaian selanjutnya. Berikut ini merupakan alat yang sangat berpengaruh bagi rangkaian papan pergantian pemain yaitu terdiri dari IC4072, IC7447, dan seven segment.

\section{IC (Integrated Circuit)}

IC (Integrated Circuit) adalah suatu media yang berisi berbagai macam komponen elektronika yang terintegrasi dan terhubung satu dengan lainnya sedemikian rupa untuk melaksanakan suatu fungsi tertentu [1].

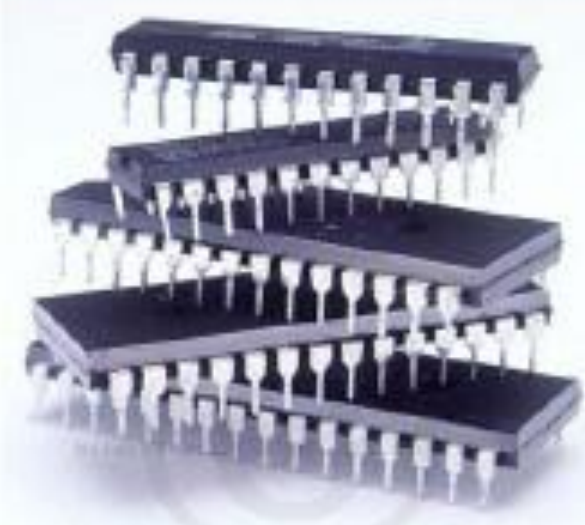

Gambar 1. IC (Integrated Circuit)

IC digunakan untuk beberapa keperluan pembuatan peralatan elektronik agar mudah dirangkai menjadi peralatan yang berukuran relatif kecil. Sebelum adanya IC, hampir seluruh peralatan elektronik dibuat dari satuan-satuan komponen (individual) yang dihubungkan satu sama lainnya menggunakan kawat atau kabel, sehingga tampak mempunyai ukuran besar serta tidak praktis. Ditinjau dari segi bahan baku, IC dibalut dalam kemasan (packages) tertentu agar dapat terlindungi dari gangguan luar seperti terhadap kelembaban debu dan kontaminasi zat lainnya. Kemasan IC dibuat dari bahan ceramic dan plastic, serta didesain untuk mudah dalam pemasangan dan penyambungannya. IC dapat bekerja dengan diberikan catuan tegangan 5 -12 volt sesuai dengan tipe IC nya.

\section{Gerbang Logika OR 4 Input}

Gerbang $O R$ ini mempunyai fungsi dual 4 in OR dengan 4 buah input dan 2 gerbang. Untuk gerbang OR dengan 4 input dan 1 output, akan bernilai 1 bila dari salah satu keempat input atau semua input tersebut bernilai 1 (tabel 1).

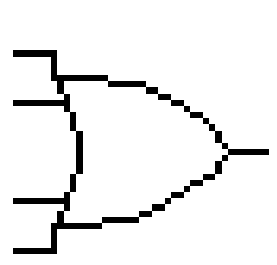

(a)

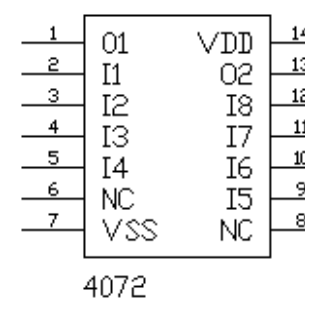

(b)
Gambar 2. Simbol (a) dan IC (b) logika OR dengan 4 input

Pada gambar di atas (IC4072), 01 dan 02 adalah output. $11,12,13,14,15,16,17,18$ adalah input. Untuk VSS sama dengan VCC (+), VDD sama dengan GND (-) sedangkan untuk $N C$ tidak digunakan atau not conector.

Tabel kebenaran logika dual 4 in $O R$ yaitu: 
Tabel 1. Truth table OR dengan 4 input

\begin{tabular}{cccccc}
\hline \multicolumn{4}{c}{ Input } & \multicolumn{3}{c}{ Output } & \multirow{2}{*}{ Kondisi } \\
\cline { 1 - 4 } A & B & C & D & Y & \\
\hline 0 & 0 & 0 & 0 & 0 & Mati \\
0 & 0 & 0 & 1 & 1 & Hidup \\
0 & 0 & 1 & 0 & 1 & Hidup \\
0 & 0 & 1 & 1 & 1 & Hidup \\
0 & 1 & 0 & 0 & 1 & Hidup \\
0 & 1 & 0 & 1 & 1 & Hidup \\
0 & 1 & 1 & 0 & 1 & Hidup \\
0 & 1 & 1 & 1 & 1 & Hidup \\
1 & 0 & 0 & 0 & 1 & Hidup \\
1 & 0 & 0 & 1 & 1 & Hidup \\
1 & 0 & 1 & 0 & 1 & Hidup \\
1 & 0 & 1 & 1 & 1 & Hidup \\
1 & 1 & 0 & 0 & 1 & Hidup \\
1 & 1 & 0 & 1 & 1 & Hidup \\
1 & 1 & 1 & 0 & 1 & Hidup \\
1 & 1 & 1 & 1 & 1 & Hidup \\
\hline
\end{tabular}

\section{Rangkaian Kombinasional}

Rangkaian kombinasional adalah rangkaian digital yang nilai output seluruhnya bergantung pada kombinasi nilai-nilai inputnya pada saat tersebut. Rangkaian kombinasional tidak dipengaruhi oleh segi historis dari rangkaian seperti halnya rangkaian sekuensial. Rangkaian kombinasional terdiri atas blok-blok gerbang logika dasar seperti gerbang $A N D, O R$, dan NOT, serta beberapa gerbang logika lainnya yang dikombinasikan untuk mendapatkan nilai keluaran tertentu.

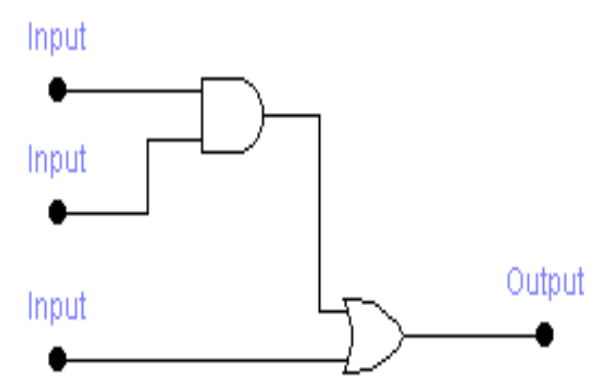

Gambar 3. Contoh rangkaian kombinasional
Tabel 2. Sistem bilangan digital

\begin{tabular}{ccc}
\hline Sistem & $\begin{array}{c}\text { Radiks } \\
(\mathbf{r})\end{array}$ & Himpunan Digit \\
\hline Desimal & 10 & $\{0,1,2,3,4,5,6,7,8,9\}$ \\
Biner & 2 & $\{0,1\}$ \\
Oktal & 8 & $\{0,1,2,3,4,5,6,7\}$ \\
$\begin{array}{c}\text { Heksa } \\
\text { desimal }\end{array}$ & 16 & $\{0,1,2,3,4,5,6,7,8,9$ \\
& & $\mathrm{A}, \mathrm{B}, \mathrm{C}, \mathrm{D}, \mathrm{E}, \mathrm{F}\}$ \\
\hline
\end{tabular}

\section{Rangkaian BCD (Binary Code Decimal)}

Untuk menghubungkan antara perhitungan yang dilakukan oleh manusia dengan perhitungan yang dilakukan oleh sistem digital perlu adanya suatu sistem yang dapat melakukan perubahan (konversi) dari bentuk biner ke dalam bentuk desimal. Perubahan tersebut dapat dilakukan dengan menggunakan sistem sandi atau kode. Salah satu sistem sandi yang dipergunakan untuk merubah dari bilangan biner menjadi bilangan desimal disebut sandi BCD (binary code decimal).

Untuk menyandi bilanganbilangan desimal dapat dilakukan dengan menggunakan angka biner 4 bit (binary digit) sehingga akan diperoleh 16 kemungkinan kombinasi 4 bit bilangan biner.

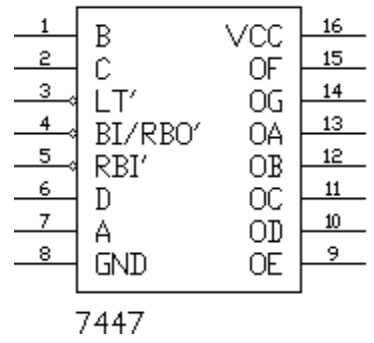

Gambar 4. IC logika BCD

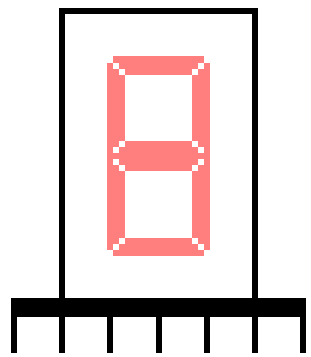

Gambar 5. Display seven segment 
Tabel 3. Konversi biner ke

\begin{tabular}{ccc}
\multicolumn{3}{c}{ hexadesimal dan desimal } \\
\hline Biner & Hexadesimal & Desimal \\
\hline 0000 & 0 & 0 \\
0001 & 1 & 1 \\
0010 & 2 & 2 \\
0011 & 3 & 3 \\
0100 & 4 & 4 \\
0101 & 5 & 5 \\
0110 & 6 & 6 \\
0111 & 7 & 7 \\
1000 & 8 & 8 \\
1001 & 9 & 9 \\
1010 & $\mathrm{~A}$ & 10 \\
1011 & $\mathrm{~B}$ & 11 \\
1100 & $\mathrm{C}$ & 12 \\
1101 & $\mathrm{D}$ & 13 \\
1110 & $\mathrm{E}$ & 14 \\
1111 & $\mathrm{~F}$ & 15 \\
\hline
\end{tabular}

\section{Seven Segment}

Seven segment merupakan rangkaian pendisplay angka yang terdiri dari beberapa dioda cahaya (LED) yaitu LED untuk pembentukan angka dan satu LED sebagai titik seperti pada gambar 5 . Ada dua jenis LED berdasarkan kaki yang di pakai bersama-sama (common), yaitu common anoda dan common katoda. Untuk memudahkan dalam menyalakan seven segment, maka di butuhkan decoder khusus untuk mengkodekan dari kode biner menjadi kode-kode biner yang sesuai untuk membentuk display angka. Ada dua driver umum yang dipakai sebagai decoder ke seven segment yaitu BCD to seven segment dengan menggunakan IC7447 dan IC7432

\section{HASIL DAN PEMBAHASAN}

Papan pergantian pemain ini menggunakan IC4072, IC7447, dan seven segment. IC4072 (2 gerbang OR dengan 4 input) merupakan komponen rangkaian yang menggunakan gerbang OR. Jika salah satu atau semua inputan bernilai 1, maka output bernilai 1 (tabel 1). Rangkaian ini menggunakan IC4072 sebab dalam perakitan ini tidak membutuhkan banyak komponen IC4072.

IC7447 merupakan

komponen rangkaian BCD (binary code decimal) yang berguna untuk mengkonversi bilangan biner ke desimal. Input dari IC4072 yang masih dalam sistem bilangan biner akan dikonversi ke desimal melalui input dari IC7447 yang kemudian hasil dari output dihubungkan ke kaki - kaki seven segment.

Seven segment disini berguna untuk menampilkan hasil output yang telah dikonversi (biner ke desimal). Seven segment merupakan rangkaian pendisplay angka yang terdiri dari beberapa dioda cahaya (LED) yaitu LED untuk pembentukan angka dan satu LED sebagai titik. Ada dua jenis LED untuk berdasarkan kaki yang di pakaibersama-sama (common), yaitu common anoda dan common katoda.

\section{SIMPULAN DAN REKOMENDASI}

Setelah menyelesaikan uji coba pada rangkaian sistem digital, maka dapat diambil kesimpulan yaitu IC4072 dapat digunakan dalam perakitan papan digital karena IC4072 terdiri dari 2 gerbang OR dengan 4 inputan sehingga tidak membutuhkan banyak komponen IC4072.

IC7447 dapat digunakan untuk mengkonversi bilangan biner menjadi bilangan desimal. Penggunaan IC dalam rangkaian ini lebih efisien daripada menggunakan mikrokontroler. Biaya yang dibutuhkan lebih murah dan kerusakan yang dialami seperti human error dapat segera ditangani seketika tanpa harus menggunakan code komputer sehingga dapat meningkatkan efisiensi waktu dalam pertandingan. 
Tabel 4. Hasil uji coba rangkaian sistem digital

\begin{tabular}{|c|c|c|c|c|c|c|c|}
\hline \multicolumn{4}{|c|}{ Input (IC7447) } & \multirow[b]{2}{*}{ Hexadesimal } & \multirow[b]{2}{*}{ Desimal } & \multicolumn{2}{|c|}{ Display Seven Segment } \\
\hline D & C & B & A & & & Papan Breadboard & $\begin{array}{l}\text { Electronic } \\
\text { Workbencl }\end{array}$ \\
\hline 0 & 0 & 0 & 0 & 0 & 0 & & \\
\hline 0 & 0 & 0 & 1 & 1 & 1 & & \\
\hline 0 & 0 & 1 & 0 & 2 & 2 & & 1 \\
\hline 0 & 0 & 1 & 1 & 3 & 3 & & ב \\
\hline 0 & 1 & 0 & 0 & 4 & 4 & & \\
\hline 0 & 1 & 0 & 1 & 5 & 5 & & \\
\hline 0 & 1 & 1 & 0 & 6 & 6 & & a \\
\hline 0 & 1 & 1 & 1 & 7 & 7 & & \\
\hline 1 & 0 & 0 & 0 & 8 & 8 & & $\theta$ \\
\hline 1 & 0 & 0 & 1 & 9 & 9 & & \\
\hline
\end{tabular}




\section{DAFTAR PUSTAKA}

[1] A. D. W. Sumari. "Teknologi Integrated Circuit (IC) : Menuju Airforce Industry". 1999.

[2] D. Rusmadi. "Digital \& Rangkaian”. Bandung: CV.Pionir Jaya. 2000.

[3] F. Kurniawan. "Sistem Digital Konsep dan Aplikasi". Yogyakarta: Gava Media. 2005.

[4] L. R. Tokheim. "Elektronika Digital". Jakarta: Erlangga. 1990.

[5] Modul Praktikum Rangkaian Digital. Jurusan Teknik Informatika, Fakultas Sains dan Teknologi, Universitas Islam Negeri Maulana Malik Ibrahim Malang.

[6] Modul Praktikum Sistem Digital. Laboratorium Sistem Digital, Program Studi Teknik Informatika, Universitas Trunojoyo. 2010.
[7] Modul Teknik Digital. Laboratorium Teknik Digital, Yayasan Sandhykara Putra Telkom, SMK Telkom Sandhy Putra Malang. 2008.

[8] P. Allen. "The Practice of Analog IC Design". IEEE Santa Clara Valley Solid-State Circuits Chapter. May 13, 2004.

[9] P. I. Santoso. "Teknik Digital". Yogyakarta: Andi. 2001.

[10] S. Febriyanto, R. Regustus. "Analisis Gerbang Logika Analog NOR Dengan Software Simulasi EWB512". Laboratorium Teknik Elektro, Jurusan Teknik Elektro, Universitas Bengkulu. 2008.

[11] S. W. Jones. "Introduction to Integrated Circuit Technology (Fourth Edition)". IC Knowledge LLC. 